\title{
Shear capacity in concrete beams reinforced by stirrups with two different inclinations
}

\author{
Piero Colajanni ${ }^{\mathrm{a}, *}$, Lidia La Mendola $^{\mathrm{a}}$, Giuseppe Mancini ${ }^{\mathrm{b}}$, Antonino Recupero $^{\mathrm{c}}$, Nino Spinella $^{\mathrm{c}}$ \\ ${ }^{a}$ Dipartimento di Ingegneria Civile, Ambientale, Aerospaziale e dei Materiali, University of Palermo, Palermo, Italy \\ ${ }^{\mathrm{b}}$ Dipartimento di Ingegneria Strutturale e Geotecnica, Politecnico di Torino, Turin, Italy

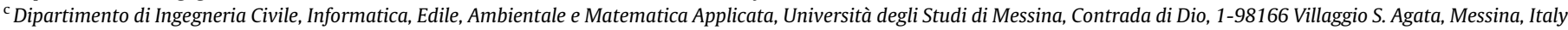

\section{A R T I C L E I N F O}

\section{Article history:}

Received 7 April 2014

Revised 7 August 2014

Accepted 6 October 2014

\section{Keywords:}

Shear strength

Different inclined stirrups

Analytical model

Plastic model

Stress field

\begin{abstract}
A B S T R A C T
A model for the estimation of shear capacity in Reinforced Concrete (RC) beams with web reinforcement is provided by introducing a generalization of classical plastic Nielsen's model, which is based on the variable-inclination stress-field approach. The proposed model is able to predict the shear capacity in RC beams reinforced by means of stirrups having two different inclinations and longitudinal web bars.

A numerical comparison with the results of experimental tests and those provided by a Finite Element Model (FEM) based on the well known theory of Modified Compression Field Theory (MCFT) is carried out for validating the robustness of the proposed model.

Finally, a set of parametrical analyses demonstrates the efficiency of the proposed double transversereinforcement system in enhancing the shear capacity of RC beams.
\end{abstract}

(C) 2014 Elsevier Ltd. All rights reserved.

\section{Introduction}

In the last decades, many theoretical and experimental investigations have clarified several significant aspects of shear collapse in Reinforced Concrete (RC) and Prestressed Concrete (PC) elements [1-14]. The first model for shear strength prediction of RC beams, introduced by Ritter and Mörsch [15,16], was based on the truss analogy, where the contribution of the concrete is given by diagonal compression struts with a fixed $45^{\circ}$ slope. In the last years, it has been replaced by a new model based on plastic theory [17-21]. In particular, this model assumes a compressive stress field in the concrete, and an equivalent uniformly distributed tensile stress field corresponding to the action of the stirrups. In this approach the inclination angle $\theta$ of the compressive stresses may be different from $45^{\circ}$. In fact, after yielding of web reinforcements, the inclination angle $\theta$ varies as the shear force increases. This approach is included in the models accepted in international codes $[22,23]$ for the design of transversely-reinforced RC structural members subjected to shear.

The plastic model has also been adapted for the case of Fibre Reinforced Concrete (FRC) beams with or without stirrups [24-28].

\footnotetext{
* Corresponding author.

E-mail addresses: piero.colajanni@unipa.it (P. Colajanni), lidia.lamendola@ unipa.it (L. La Mendola), giuseppe.mancini@polito.it (G. Mancini), antonino. recupero@unime.it (A. Recupero),nino.spinella@unime.it (N. Spinella).
}

Nowadays, a new way for the transverse reinforcement of RC beams in shear is gaining, attractiveness characterized by two different inclinations of shear reinforcement. This layout is being adopted in various structural typologies as: (a) in deep beams often used in bridges, reinforced with both stirrups inclined at two different angles $\left(90^{\circ}\right.$ and $\left.45^{\circ}\right)$ and longitudinal reinforcement; (b) in semi-precast Hybrid Steel-Trussed Concrete Beams (HSTCB), consisting in a prefabricated steel truss embedded in a cast-in-situ concrete beam [29-32]. Moreover, the use of two different inclinations of shear reinforcement was very common in the design of beams in the past in RC frame. The upper longitudinal reinforcements in the region close to the beam to column joints were bent at $45^{\circ}$ downwards, where they were not needed for bending moment anymore.

In the past codes, where the contribution due to concrete and steel reinforcement were additive, the contribution of multiple inclination of reinforcement could be easily taken into account by adding the contributions.

Currently, the design codes contain no specific provisions for the above-mentioned structural cases, and their design can be performed only by adjusting the existing models developed for other structural typologies.

For instance, referring to typology (b) and according to the recently-issued Italian guidelines on HSTCBs [33], the contribution of the transverse reinforcement exhibiting an inclination close to that of the concrete struts in compression should be neglected, 
and only the reinforcement in tension should be considered. As an alternative, the shear resistance may be evaluated either by enlarge the range of the inclination angle of the compressed concrete strut [30] or, again, by means of an additive approach, considering the steel truss as an additional resistant system associated to the remaining unreinforced concrete beam (shear capacity = capacity of the unreinforced concrete beam + capacity of the classical Mörsch truss) [32].

However, though sophisticated nonlinear FEM analyses, can be nowadays performed using accurate models [8,34-36], simplified mechanical simplified robust models are still needed, to speed up the design and to make the analysis of the various phases of the construction easier.

In this context, a physical model for the evaluation of the shear capacity in beams containing (a) two sets of stirrups with different inclinations, and (b) web longitudinal reinforcement is formulated by means of a suitable modification of a model proposed in previous paper $[20,21,38]$, by extending the classical model currently proposed in Eurocode2 [22]. The model is validated by favorable comparison against the results of experimental tests on HSTCBs [32] and FEM analyses performed by using the FEM code VecTor2 [42] on traditional RC beams, because for this typology the authors have not found tests on RC beams with two orders of stirrups in the literature. The analyses demonstrate the efficiency of the proposed model in estimating the shear capacity.

\section{Proposed model}

The proposed model, aiming at evaluating the shear capacity of concrete beams reinforced with two differently-inclined series of stirrups, is based on the model derived in $[20,21,38]$ where the following assumptions were made: (i) at the Ultimate Limit State (ULS), the resistant mechanism can be represented (Fig. 1) by: two chords; the top compressed chord is made by the concrete and its reinforcement, the bottom tensile one made by the bottom longitudinal reinforcement as well as the prestressing reinforcement (if any); - and the web, carrying the shear action, made of concrete, longitudinal web reinforcement (if any), and the stirrups); (ii) both the stirrups and the longitudinal web reinforcement (if any) are subjected to a purely axial force (i.e. dowel action is considered elsewhere, as explained in the following); (iii) compared to the size of the structural members, the spacing of the stirrups and of the web longitudinal bars is so small that their actions can be modeled via different uniform stress fields; (iv) the concrete stress field in the web is inclined by the angle $\theta$ to the longitudinal axis, which may differ from $\beta \sim 45^{\circ}$ that is the alignment of the first cracks in a structural member subjected merely to bending and shear (like a beam at the Service Limit State SLS); the maximum shear capacity is achieved for $\operatorname{ctg} \theta$ varying in the range $1 \leqslant \operatorname{ctg} \theta \leqslant(\operatorname{ctg} \theta)_{\max }$ [39]; usually the value $(\operatorname{ctg} \theta)_{\max }=2.5$ is assumed [22]; more severe limitation must be imposed in elements where flexural ductility is demanded [40]; (v) the constitutive laws of the materials are consistent with the theory of plasticity; (vi) the contributions to the shear capacity of dowel action, aggregate interlock are indirectly taken care of by introducing (through the angle $\theta$ ) different orientations for the principal directions of the stress fields and the cracks; (vii) the contribution due to the tensile strength of concrete $\left(V_{c}\right)$ is neglected; (viii) the arch action, which plays a remarkable role in the $D$ (Disturbed) regions, is neglected; hence, the validity of the model is limited to $B$ (Bernoulli) regions.

It has to be pointed out that according to [19], assumption (iv) may be used for beam with a transverse minimum shear reinforcement mechanical ratio of $0.16 / f_{c}^{0.5}$ being $f_{c}$ the concrete strength in compression.

The model is now extended to beams having two sets of web stirrups distributed along two different inclinations $\alpha_{1}$ and $\alpha_{2}$; they can be subjected either to compression or tension, depending on their inclination with respect to the longitudinal axis; thus internal actions in the web are modeled via four uniform stress fields, namely an horizontal one representing the longitudinal web reinforcement, the one representing the compressed concrete inclined by the angle $\theta$ and two representing the action of the two order of stirrups inclined by the angles $\alpha_{1}$ and $\alpha_{2}$, respectively (Fig. 1b).

The proposed model is formulated by applying the static theorem of the theory of plasticity, that makes it possible to evaluate the shear capacity of a beam via the so-called "lower-bound solution".

In order to derive the equilibrium equations, the following notation is introduced: $A_{t w 1}, s_{t w 1}$ and $A_{t w 2}, s_{t w 2}$ are the areas of the cross-sections and the spaces of the reinforcement in the web with orientation $\alpha_{1}$ and $\alpha_{2}$ respectively; $A_{l w}$ the area of the longitudinal reinforcement in the web; $b_{w}$ and $h$ the minimum web width and the depth of the cross section, respectively; $f_{y d}$ and $f^{\prime}{ }_{c d}$ the design steel strength and the reduced concrete strength in compression, respectively; hence, being $A_{t w i}$ the area of generic transverse reinforcement, the mechanical ratios $\omega_{t w i}(i=1,2)$ are: $\omega_{t w i}=A_{t w i} /\left(b_{w}\right.$ $\left.s_{t w i} \sin \alpha_{i}\right) \times\left(f_{y d} / f^{\prime}{ }_{c d}\right)$; likewise, $A_{l w}$ is the area of the longitudinal reinforcement in the web and the mechanical ratio is $\omega_{l w}=$ $A_{l w} /\left(b_{w} h\right) \times\left(f_{y d} / f^{\prime}{ }_{c d}\right)$.

It has to be emphasized that, in order to take into account the biaxial stress state in the web, an "effectiveness" coefficient $v^{\prime}$ $(\leqslant 1)$ has been applied to the design compressive strength of the concrete $f_{c d}$ for the concrete web stress field, namely $f^{\prime}{ }_{c d}=$ $v^{\prime} f_{c d}[22]$.

Aiming at evaluating the shear capacity of the beam, the following equilibrium equations of three different segments of the beam obtained by three different inclined sections parallel to either the direction of the concrete or one of the two orders of stirrups stress field are derived as shown in Appendix A:

$$
\begin{aligned}
v(x)= & \tilde{\sigma}_{t w 1} \cdot \omega_{t w 1} \cdot\left(\operatorname{ctg} \theta+\operatorname{ctg} \alpha_{1}\right) \cdot \sin ^{2} \alpha_{1}+\tilde{\sigma}_{t w 2} \cdot \omega_{t w 2} \\
& \cdot\left(\operatorname{ctg} \theta+\operatorname{ctg} \alpha_{2}\right) \cdot \sin ^{2} \alpha_{2}
\end{aligned}
$$
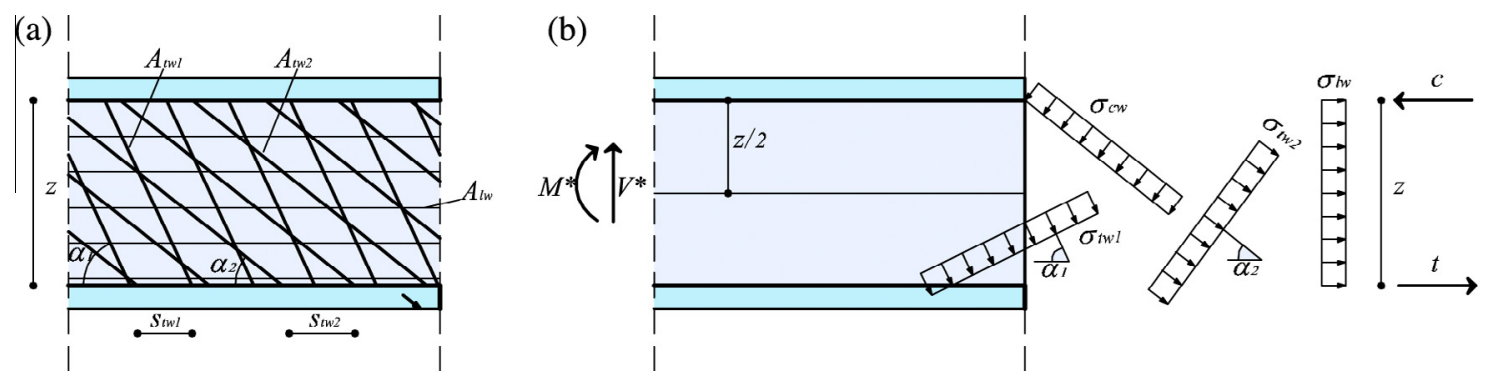

Fig. 1. Different types of reinforcement in a beam segment: (a) structural layout and (b) stress fields. 


$$
\begin{aligned}
v(x)= & \tilde{\sigma}_{c w} \cdot\left(\operatorname{ctg} \theta+\operatorname{ctg} \alpha_{2}\right) \cdot \sin ^{2} \theta+\omega_{t w 1} \cdot \tilde{\sigma}_{t w 1}\left(\operatorname{ctg} \alpha_{1}-\operatorname{ctg} \alpha_{2}\right) \\
& \cdot \sin ^{2} \alpha_{1}
\end{aligned}
$$

$$
\begin{aligned}
v(x)= & \tilde{\sigma}_{c w} \cdot\left(\operatorname{ctg} \theta+\operatorname{ctg} \alpha_{1}\right) \cdot \sin ^{2} \theta+\omega_{t w 2} \cdot\left(\operatorname{ctg} \alpha_{2}-\operatorname{ctg} \alpha_{1}\right) \\
& \cdot \tilde{\sigma}_{t w 2} \cdot \sin ^{2} \alpha_{2}
\end{aligned}
$$

$$
\begin{aligned}
\widetilde{C}(x)= & m(x)-0.5 f_{y d}\left[\omega_{t w 1} \tilde{\sigma}_{t w 1}\left(\operatorname{ctg}^{2} \theta-\operatorname{ctg}^{2} \alpha_{1}\right) /\left(1+\operatorname{ctg}^{2} \alpha_{1}\right)\right. \\
& \left.+\omega_{t w 2} \tilde{\sigma}_{t w 2}\left(\operatorname{ctg}^{2} \theta-\operatorname{ctg}^{2} \alpha_{2}\right) /\left(1+\operatorname{ctg}^{2} \alpha_{2}\right)-\omega_{l w} \tilde{\sigma}_{l w}\right]
\end{aligned}
$$

$$
\begin{aligned}
\widetilde{T}(x)= & m(x)+0.5\left[\omega_{t w 1} \tilde{\sigma}_{t w 1}\left(\operatorname{ctg}^{2} \theta-\operatorname{ctg}^{2} \alpha_{1}\right) /\left(1+\operatorname{ctg}^{2} \alpha_{1}\right)\right. \\
& \left.+\omega_{t w 2} \tilde{\sigma}_{t w 2}\left(\operatorname{ctg}^{2} \theta-\operatorname{ctg}^{2} \alpha_{2}\right) /\left(1+\operatorname{ctg}^{2} \alpha_{2}\right)-\omega_{l w} \tilde{\sigma}_{l w}\right]
\end{aligned}
$$

where $\tilde{\sigma}_{t w 1} \tilde{\sigma}_{t w 2}$ and $\tilde{\sigma}_{c w}$ are the stresses of two stirrup fields and of concrete field in the web respectively, made dimensionless with respect to the steel design strength $f_{y d}$ and the reduced concrete strength in compression $f^{\prime}{ }_{c d}$ respectively, $v(x), \widetilde{C}(x)$ and $\widetilde{T}(x)$ the shear and the total forces in the compression and tension chords along the abscissa $x$, made dimensionless with respect to $b_{w} z f^{\prime}{ }_{c d}$, and $m(x)$ the bending moment made dimensionless with respect to $b_{w} z^{2} f^{\prime}{ }_{c d}$, where $d$ denotes the effective depth of the beam section, and $z$ is the lever $\operatorname{arm}(z=j d)$.

Let us stress that usually the bending moment in literature is made dimensionless with respect to $b_{w} z^{2} f_{c d}$, i.e. a value of the dimensionless moment $1 / v^{\prime}$ times greater is here obtained.

The shear capacity of the beam can be evaluated by applying the static theorem of the theory of plasticity, that yields an estimation of the beam strength as the maximum value of the solutions verifying the equilibrium conditions [Eqs. 1-5], and that satisfy the following conditions of "plastic admissibility":

$0 \leqslant\left(\tilde{\sigma}_{c w}, \tilde{\sigma}_{t w 1}, \tilde{\sigma}_{t w 2}\right) \leqslant 1$

$\widetilde{T}(x) \leqslant \omega_{s}-\omega_{s}^{\prime} \leqslant \widetilde{C}(x) \leqslant \xi / v^{\prime}+\omega_{s}^{\prime}$

where $\xi=x / z$ is the dimensionless neutral axis depth, $A_{s}^{\prime}, \omega^{\prime}{ }_{s}=$ $A_{s}^{\prime} /\left(b_{w} z f^{\prime}{ }_{c d}\right)$ and $A_{s}, \omega_{s}=A_{s} /\left(b_{w} z f^{\prime}{ }_{c d}\right)$ are the areas and the mechanical ratios of the longitudinal reinforcement in the compression and tension chords, respectively. Once again $f^{\prime}{ }_{c d}$ instead of the more common use of $f_{c d}$ is used for definition of mechanical ratios of the flexural longitudinal reinforcement.Eqs. (1)-(3), (6), and (7) provide the following form of the "plastic admissible condition" for the stress fields of the stirrups:

$0 \leqslant \omega_{t w 1} \tilde{\sigma}_{t w 1} \sin ^{2} \alpha_{1} / \sin ^{2} \theta+\omega_{t w 2} \tilde{\sigma}_{t w 2} \sin ^{2} \alpha_{2} / \sin ^{2} \theta \leqslant 1$

This equation reflects the interaction between the stress fields in the stirrups and it is the main modification with respect to previous models for single inclination of the stirrups.

\section{Evaluation of the shear capacity}

In order to evaluate the shear capacity by means of the "lowerbound solution", the shear strength in Eq. (1) (or in Eqs. (2) and (3)) has to be maximized, by variation of $\tilde{\sigma}_{t w 1}, \tilde{\sigma}_{t w 2}$ and $\operatorname{ctg} \theta$ according to the ranges specified in Eqs. (6)-(8). Thus, for the solution of the problem of nonlinear programming, a specific algorithm provided by the software "Solver" of Microsoft Excel ${ }^{\circledR}$ was adopted. This software uses the code of nonlinear optimization "Generalized Reduced Gradient (GRG2)" [41] developed by Leon Lasdon at the University of Texas (Austin, Texas - USA) and Allan Waren at the University of Cleveland (Cleveland, Ohio - USA).

\subsection{Numerical corroboration against experimental and FEM analyses}

With the aim to validate the robustness of the proposed model, firstly the results of an experimental survey on Hybrid Steel Trussed-Concrete Beams (HSTBs) are reproduced. HSTCBs are a typical Italian structural typology constituted by a precast steel truss embedded into a concrete core generally cast in situ. Among several existing HSTCB typologies, test on shear critical beams depicted in Fig. 2a and b were performed in [32]. The beams were made up of: - a steel plate placed at the bottom of the beam in some cases joined by welding with steel rebars, the whole acting as the bottom chord of the truss; - coupled steel bars constituting the upper chord; - steel inclined web bars welded to the two chord elements. Beams characterized by different type (smooth or ribbed) and number of bottom rebar welded to the plate, type of steel (B450C or S355) of the web and chord rebars were considered. Namely, three different number of bottom rebars $(0,3,5)$ according to cross section shown in Fig. 2c-e were considered, resulting into a total number of 9 specimens. They are identified by the code X\#-J-K; the code X identifies the type of the top chord $\operatorname{rebar}(\mathrm{X}=\mathrm{R}$ : ribbed, $\mathrm{X}=\mathrm{S}$ : smooth); \# the number of bottom rebar; $\mathrm{J}$ the type of chord rebar steel $(\mathrm{J}=\mathrm{B}=\mathrm{B} 450 \mathrm{C}, \mathrm{J}=\mathrm{S}=\mathrm{S} 355)$; $\mathrm{K}$ the type of web reinforcement steel $(K=B=B 450 C, K=S=S 355)$. All specimens have $4 \phi 40$ as top rebar and $2 \phi 16$ with spacing of $450 \mathrm{~mm}$ as web reinforcement.

Each type and diameter of reinforcing bars were tested, resulting in a yielding stress of $f_{s y}=479 \mathrm{MPa}$ and $f_{s y}=551 \mathrm{MPa}$ for steel B450C (ribbed), for diameters $\phi=40 \mathrm{~mm}$ and $\phi=16 \mathrm{~mm}$ respectively, and $f_{s y}=413 \mathrm{MPa}, f_{s y}=402 \mathrm{MPa}$, and $f_{s y}=397 \mathrm{MPa}$ for steel S355 (smooth), for diameters $\phi=40 \mathrm{~mm}$ and $\phi=16 \mathrm{~mm}$ and for the bottom plate (thickness $16 \mathrm{~mm}$ ). Concrete mechanical parameters were mean compressive strength $f_{c m}=38.83 \mathrm{MPa}$ and mean tensile strength $f_{c t m}=3.36 \mathrm{MPa}$. In Table 1 the characteristics of the 9 specimens are summarized.

In the test survey, all the specimens failed in shear with inclined cracks spreading after debonding, cracks between steel plate and concrete, and collapse of transversal reinforcement.

Regarding the assessment of beam strength by the proposed model, it has to be stressed that for this typology some inaccuracy can arises from the assumption $i v$ ) in Section 2, since the spacing of web shear reinforcement is large; however, the specimens taken into account have a shear reinforcement ratio $\omega_{s w}=0.061$, larger than $\omega_{s w, \min }=0.16 / f^{\prime}{ }_{c}{ }^{0.5}=0.0257$. Thus, they satisfy the minimum requirements to be analyzed by the truss model.

Moreover, for the assessment of collapse load by the numerical model, for simplicity's sake the distance between the two chords (the lever arm) is settled as $z=0.9 d$, and two values of the maximum slope of the concrete stress field are assumed, namely those corresponding to $\operatorname{ctg} \theta_{\max }=2.5$ and $\operatorname{ctg} \theta_{\max }=3$. Finally, the critical section was selected as the section with maximum bending moment coupled with the maximum shear force, excluding the D region, i.e. the section at distance $d=300 \mathrm{~mm}$ at the left side of the applied load in Fig. 3.

In Table 1 the results provided by the proposed model (where the material strengths above mentioned without any partial safety factor were introduced) and the experimental tests are compared. The mean value of the ratios between numerical and experimental results, equal to 0.89 , and 1.01 respectively, and the small value of their Coefficient of Variation ( $\mathrm{CoV}$ ), equal to $9.42 \%$, and $6.33 \%$ respectively, prove the efficiency of the model, that provide a precautionary assessment of the collapse load if the former assumption is retained $\left(\operatorname{ctg} \theta_{\max }=2.5\right)$ and a very efficient assessment if the latter $\left(\operatorname{ctg} \theta_{\max }=3\right)$ is considered.

For ordinary RC beams a numerical comparison with the results provided by a FEM was carried out, since the authors have not found tests on RC beams with two orders of stirrups in literature. 
(a)

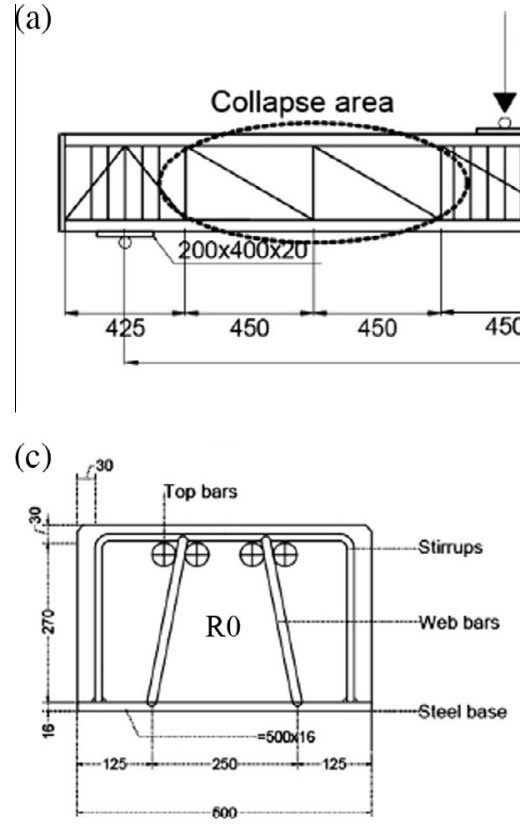

$\mathrm{P}$

$200 \times 400 \times 20$
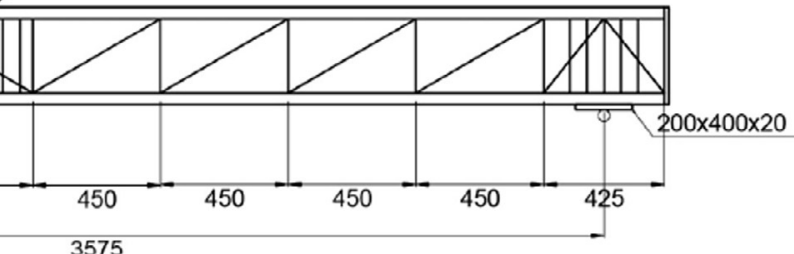

(b)

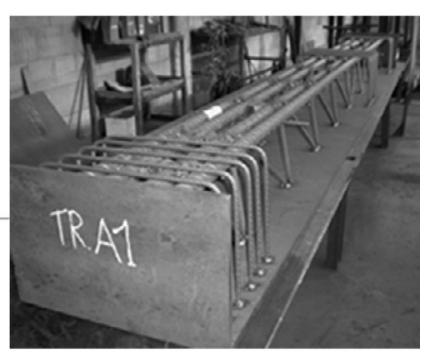

(d)

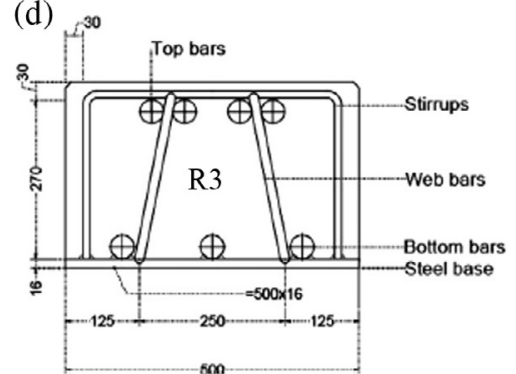

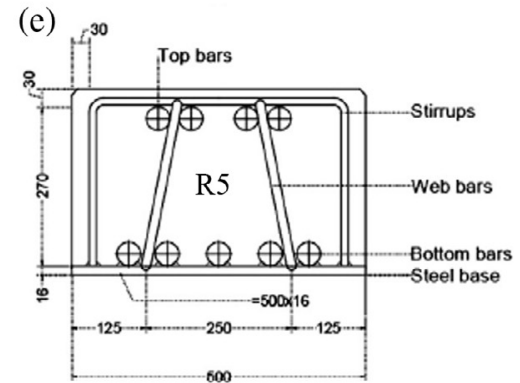

Fig. 2. Tested beams [32]: (a) structural scheme and dimensions; (b) view; (c)-(e) cross sections.

Table 1

Reinforcing bar types, model and experimental collapse loads, and their ratios.

\begin{tabular}{|c|c|c|c|c|c|c|c|c|}
\hline \multirow[t]{2}{*}{ Code } & \multirow[t]{2}{*}{ Bottom rebar } & \multirow[t]{2}{*}{ Chord steel } & \multirow[t]{2}{*}{ Web steel } & \multicolumn{2}{|c|}{$V_{u}$ Model $(\mathrm{kN})$} & \multirow[t]{2}{*}{$V_{u}$ Exp. $(\mathrm{kN})$} & \multirow{2}{*}{$\begin{array}{l}\text { Model/exp. } \\
\operatorname{ctg} \theta_{\max }=2.5\end{array}$} & \multirow{2}{*}{$\begin{array}{l}\text { Model/exp. } \\
\operatorname{ctg} \theta_{\max }=3\end{array}$} \\
\hline & & & & $\operatorname{ctg} \theta_{\max }=2.5$ & $\operatorname{ctg} \theta_{\max }=3$ & & & \\
\hline R0-B-B & l & B450C & B450C & 861 & 861 & 861 & 1.00 & 1.00 \\
\hline R0-B-S & 1 & B $450 \mathrm{C}$ & S355 & 754 & 836 & 865 & 0.87 & 0.97 \\
\hline RO-S-B & 1 & S355 & B $450 \mathrm{C}$ & 861 & 861 & 856 & 1.01 & 1.01 \\
\hline R3-B-B & $3 \phi 40$ & B450C & B450C & 898 & 1057 & 1078 & 0.83 & 0.98 \\
\hline R3-B-S & $3 \phi 40$ & B450C & S355 & 754 & 883 & 929 & 0.81 & 0.95 \\
\hline R3-S-B & $3 \phi 40$ & S355 & B450C & 898 & 1057 & 931 & 0.96 & 1.13 \\
\hline R5-B-B & $5 \phi 40$ & B450C & B $450 \mathrm{C}$ & 898 & 1057 & 1048 & 0.86 & 1.01 \\
\hline R5-B-S & $5 \phi 40$ & B450C & S355 & 754 & 883 & 975 & 0.77 & 0.91 \\
\hline \multirow[t]{4}{*}{ R5-S-B } & $5 \phi 40$ & S355 & B450C & 898 & 1057 & 1027 & 0.87 & 1.03 \\
\hline & & & & & & Mean & 0.89 & 1.01 \\
\hline & & & & & & St. dev. & 0.08 & 0.06 \\
\hline & & & & & & $\mathrm{COV}$ & $9.42 \%$ & $6.33 \%$ \\
\hline
\end{tabular}

In order to choose the FEM, it has to be emphasized that many analytical formulations were suggested in the literature to predict the behavior of RC elements subject to general load conditions, using models based on different mechanical theories and constitutive laws $[1,18,35,36]$. Among these, a general model for prediction of the load-deformation behavior of plane cracked RC elements subjected to shear and flexure is the MCFT formulated by Vecchio and Collins [8].

In the MFCT the principal strain direction is assumed to be the same of the principal stress directions. This assumption was recently removed by Vecchio [42] in the Disturbed Stress Field Model (DSFM). The DSFM explicitly incorporates rigid slipping along crack surfaces into the compatibility relations for the element. Thus the DSFM, as opposite of MCFT, allows for a divergence of the angles of inclination of average principal stress and apparent average principal strain in the concrete.

The behavior of RC is modeled summing the concrete stresses in the principal directions with reinforcement stresses, and the reinforcing bars are treated as truss elements able to transmit axial stress only. Therefore, strains in the cracked concrete and strains in the reinforcement are expressed in terms of average strains, as typical of smeared models, obtaining crack width by an appropriate base length.
The cracked concrete is treated as a new material with empirically defined stress-strain behavior, implementing several constitutive laws to reproduce stress-strain behavior in compression and tension of concrete and steel. However, the compression stress-strain behavior is usually different from the constitutive curve of a cylinder under axial compression, because the actual biaxial stress condition. This behavior, namely compression softening, is fully taken into account by the MCFT.

A software implementing the MCFT was developed at University of Toronto by Wong and Vecchio [37].

In order to investigate the efficiency of the proposed model in predicting the effect that double inclination of stirrups has on the shear capacity of RC members, a numerical investigation was performed evaluating the shear capacity of beams subjected to 4point bending. Five different stirrup layouts were analyzed, with stirrups placed following three different patterns (Fig. 3). Beams having the rectangular cross-section $300 \mathrm{~mm}$ wide and $600 \mathrm{~mm}$ depth, shear span of $1800 \mathrm{~mm}$ and the net length of $4600 \mathrm{~mm}$ are considered. A concrete with standard strength $\left(f^{\prime}{ }_{c}=30 \mathrm{MPa}\right)$ and a rebar steel with a yield strength $\left(f_{y}\right)$ equal to $500 \mathrm{MPa}$ were assumed. The beams were designed to be over reinforced in flexure to induce a shear collapse, thus two $\phi 32$ rebars and two $\phi 16$ rebars at the bottom and at the top of the beams were used, respectively. 

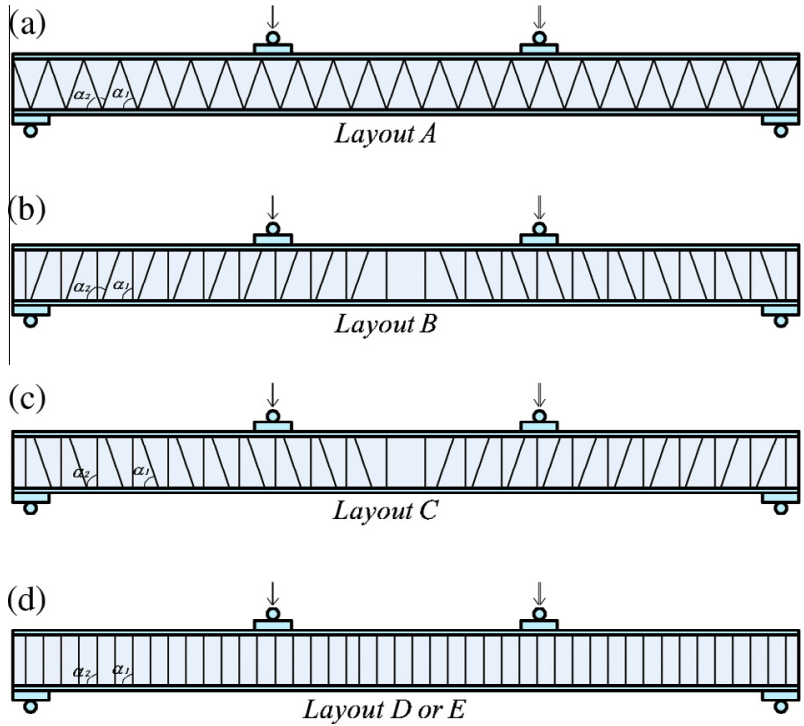

Fig. 3. Beam for the numerical analysis (net length $4.6 \mathrm{~m}$, span length $1.8 \mathrm{~m}$; cross section dimension $300 \times 600 \mathrm{~mm}$ ); Structural layouts adopted (a) A; (b) B; (c) C; and (d) D or E.

A constant geometrical percentage of transversal reinforcement $\omega_{t w 1}=\omega_{t w 2}=\omega_{w}$ was chosen equal to $0.15 \%$ independent of stirrups inclination. For the sake of simplicity, no longitudinal web reinforcement was introduced. The inclination of stirrups was varied according the parameter values described in Table 2 , with variation of $\alpha$ in the range $45^{\circ} \leqslant \alpha \leqslant 90^{\circ}$.

A two-dimensional plane stress model, suitably restrained to the symmetrical axis, was developed.

The mesh was composed (Fig. 4a) of four-node rectangular elements $50 \times 40 \mathrm{~mm}$ in size with uniform thickness to represent the concrete, two-nodes truss bars with uniform cross-sectional area for the longitudinal reinforcement, and the transversal reinforcement was applied as smeared on concrete elements of web. The numerical analyses were carried out assigning a monotonic increasing displacement on the node located at a distance equal to the shear span from the support. The total load was computed as twice the reaction force at the support. Therefore, the displacement controlled procedure was able to provide the complete loaddisplacement curve.

The sensitivity of the results to the mesh size was analyzed. As an example, in Fig. 4b the shear-displacement curves of a numerical analyses carried out by the VecTor 2 software for the case A beam having $\alpha=45^{\circ}$ and for three different mesh size are plotted. Different analyses were performed, besides those with $50 \times 40 \mathrm{~mm}$ mesh, using meshes with rectangular elements $25 \times 20 \mathrm{~mm}$ and $100 \times 80 \mathrm{~mm}$ also. The former mesh provides shear strength close to the value obtained by the $50 \times 40 \mathrm{~mm}$ mesh (Fig. 4b), while the latter provides a shear strength greater then value obtained by the $50 \times 40 \mathrm{~mm}$ mesh. Thus, for all numerical analysis shown, the mesh with rectangular elements $50 \times 40 \mathrm{~mm}$ was definitely used

The typical brittle crack pattern at shear failure is shown in Fig. 4b, while in Fig. 4c the corresponding crack pattern is shown.

Table 2

Inclination of the stirrup for A, B and C layout.

\begin{tabular}{llll}
\hline Case & $(\mathrm{A})$ & $(\mathrm{B})$ & $(\mathrm{C})$ \\
\hline$\alpha_{1}$ & $\alpha$ & $90^{\circ}$ & $\alpha$ \\
$\alpha_{2}$ & $180^{\circ}-\alpha$ & $180^{\circ}-\alpha$ & $90^{\circ}$ \\
\hline
\end{tabular}

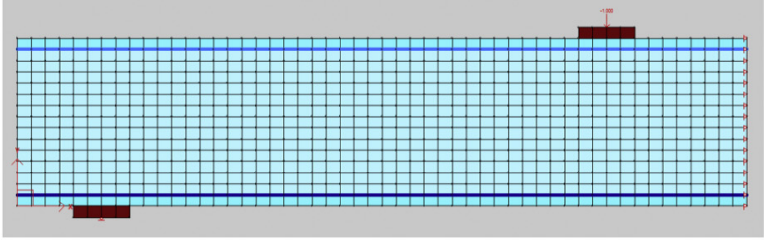

(a)

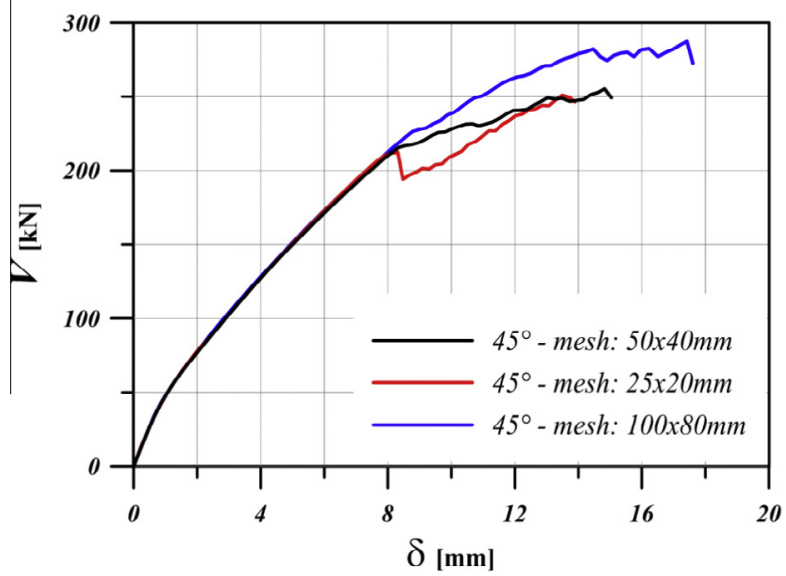

(b)
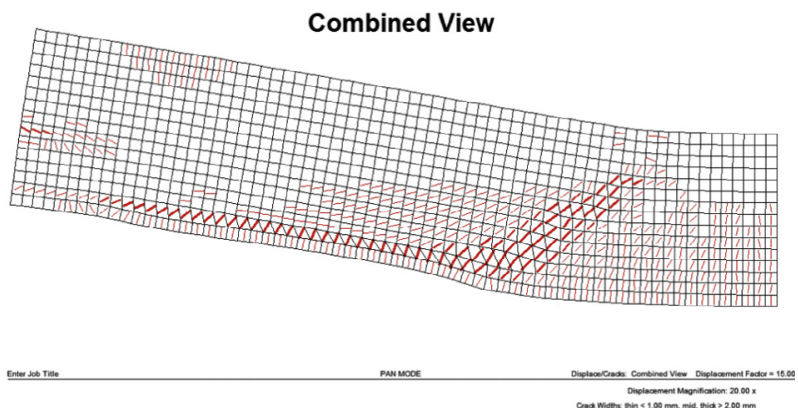

(c)

Fig. 4. Results of numerical analyses carried out by the VecTor 2 for layout A, $\alpha=45^{\circ}$ : (a) load displacement curve and (b) cracking pattern.

For the model corroboration against FEM analyses, five inclinations of stirrups $\left(45^{\circ}, 55^{\circ}, 65^{\circ}, 75^{\circ}, 90^{\circ}\right)$ for each of three layout $(A, B$, and $C)$ were analyzed by VecTor2. In Fig. 5, the values of the shear strength obtained by numerical analyses carried out for each typology as functions of stirrups inclination $(\alpha)$, are reported. They are compared against the value predicted by the proposed analytical model assuming two different values of $(\operatorname{ctg} \theta)_{\max }$, namely $(\operatorname{ctg} \theta)_{\max }=2.5$ or $(\operatorname{ctg} \theta)_{\max }=3$ to evaluate the influence of maximum allowable inclination of concrete strut on the shear strength. The analysis carried out adopting $(\operatorname{ctg} \theta)_{\max }=3$ provides an upper bound of the values obtained by VecTor2, with the only exception of layout $A$ and $\alpha=45^{\circ}$, while the results obtained assuming $(\operatorname{ctg} \theta)_{\max }=2.5$ provide always a lower bound.

\subsection{Effect of the double inclination of the stirrup}

In order to elucidate the effect that double inclination of stirrups has on the shear capacity of RC members according to the proposed model, the shear capacity of the three layouts before examined are compared with those of beams with vertical stirrup only, $\alpha_{1}=\alpha_{2}=90^{\circ}$; layout $D$ has the same total amount of stirrups of that adopted in the three layouts $(A-C)$, namely assuming 


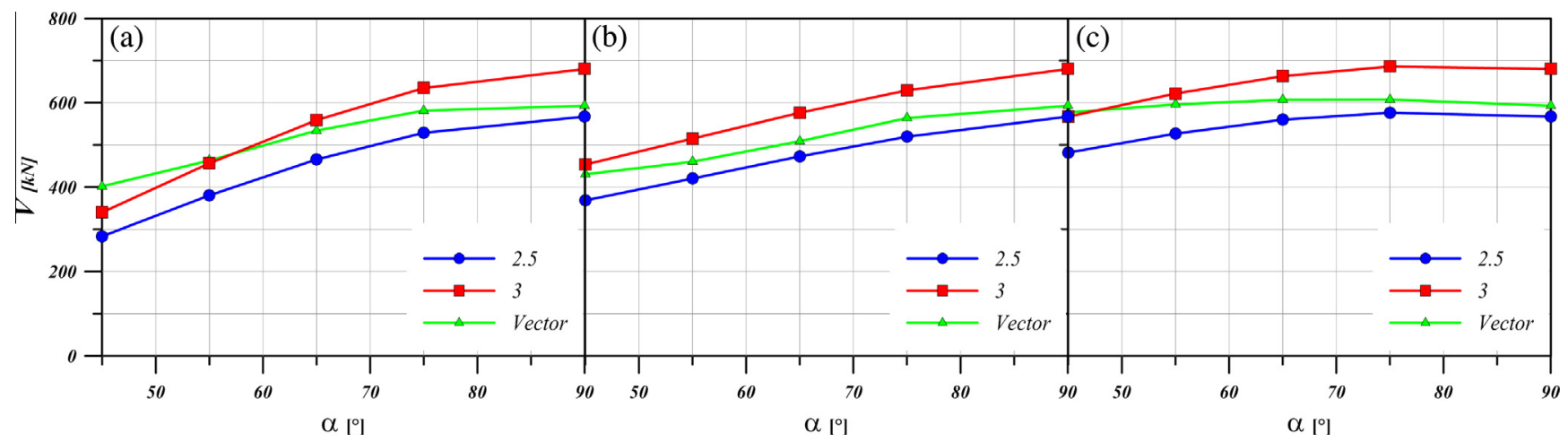

Fig. 5. Comparison of shear strength values obtained by the proposed model and FEM (VecTor2 [37]) for (a) layout A; (b) layout B; (c) layout C.

$\omega_{t w 1}=\omega_{t w 2}=\omega_{w}$; layout $E$ where the total amount is half of the previous one, assuming $\omega_{t w 1}=\omega_{t w 2}=0.5 \omega_{w}$. Namely, in layout $E$, only the transverse reinforcement arranged vertically is introduced, as in layout $D$; thus the only difference between $D$ and $E$ is that in the latter there is a transverse reinforcement percentage that is half of that introduced in layout $D$. In layouts $B$ and $C$ inclined stirrups are added with respect to layout $E$, in order to have the same total amount of stirrups as in layout $D$.

In Fig. 6 the curves of the non-dimensional shear capacity $v$ are plotted versus the stirrup angle $\alpha$ for three different values of the mechanical ratio of the stirrups $\left(\omega_{w}=0.05,0.2\right.$ and 0.4$)$, for each of the five layouts.

Comparison of the results obtained for layouts $A, B$, and $C$ characterized by differently-inclined diagonal stirrups - with those of layout $D$ demonstrates the efficiency of the layout $C$ that exhibits a good performance when the mechanical ratio of the stirrups $\omega_{w}$ is increased. Furthermore, comparing layouts $B$ and $C$ with layout $E$ makes it possible to elucidate the contribution of the inclined stirrups as such.

The plots show that layout $C$ provides the greatest capacity for any angle and for any amount of the transverse reinforcement. It is noteworthy that for $\omega_{w} \geqslant 0.2$, layout $C$ has the greatest efficiency for any stirrup inclination within the considered range, compared to the layout $E$ also, which has only vertical stirrups.

In the case of vertical stirrups, any increase of the transverse reinforcement $\omega_{w, t o t}$ above 0.4 (e.g. $\omega_{t w 1}=\omega_{t w 2}=0.2$ ) is practically ineffective, since shear capacity is controlled by the principal compression stress in the web. By contrast, in the case of inclined stirrups (even with large values of $\omega_{w, t o t}$, e.g. $\omega_{t w 1}=\omega_{t w 2}=0.4$ ) the shear capacity increases since the web reinforcement contribute to carry compression stress, as appropriately predicted by the proposed model.
Moreover, the plots show that the stirrup inclination yielding the maximum capacity is different in the three layouts $A, B$ and $C$, depending on the percentage of the total transverse reinforcement.

Summarizing, for low values of the mechanical ratio of the stirrups, inclinations close to the vertical axis give the maximum stirrups efficiency, while for high values of stirrups mechanical ratio the inclination of $45^{\circ}$ is the most effective.

With reference to the three previously-mentioned layouts, the role played by the amount of the transverse reinforcement stands out in Fig. 7, where the non-dimensional shear is plotted versus the mechanical ratio of the transverse reinforcement $\left(\omega_{t w 1}=\omega_{t w 2}=\right.$ $\left.\omega_{t w}\right)$ for a given minimum value of inclination of concrete stress field in the web and for several values of $\alpha$.

The plots confirm that the layout $C$ is, in most of the case, the most efficient, whit exception of very large values of $\omega_{w}$ for which layout $A$ is the most effective. Noteworthy, there is a value of $\omega_{w}$ for which all inclinations roughly provide the same shear capacity.

With reference to the layout $C$, for low values of stirrups mechanical ratio the vertical arrangement of the stirrups is still the most effective, but the differences with respect to the layouts with inclined stirrups are scanty indeed.

Increasing $\omega_{w}$ makes the inclinations of $45^{\circ}$ and $55^{\circ}$ the most effective, with roughly the same performance, while increasing the inclination of the stirrups brings in significant losses in terms of shear capacity.

Furthermore, the larger the stirrups amount $\left(\omega_{t w 1}=\omega_{t w 2}=\right.$ $\left.\omega_{\mathrm{w}}=1\right)$, the higher the shear capacity, that can increase even by $100 \%$ compared to the arrangement with a single set of vertical stirrups.

Finally, the relevance of the limitation introduced by the Italian Design Code on the inclination of concrete stress fields in

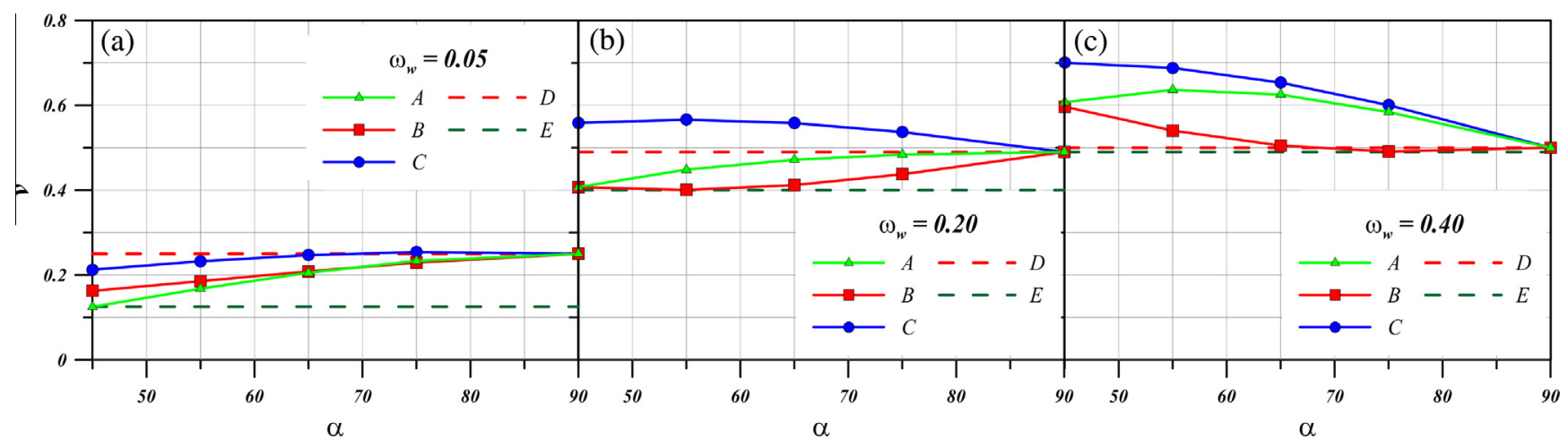

Fig. 6. Non-dimensional shear capacity for $\operatorname{ctg} \theta=2.5$ for three different amount of stirrups. 


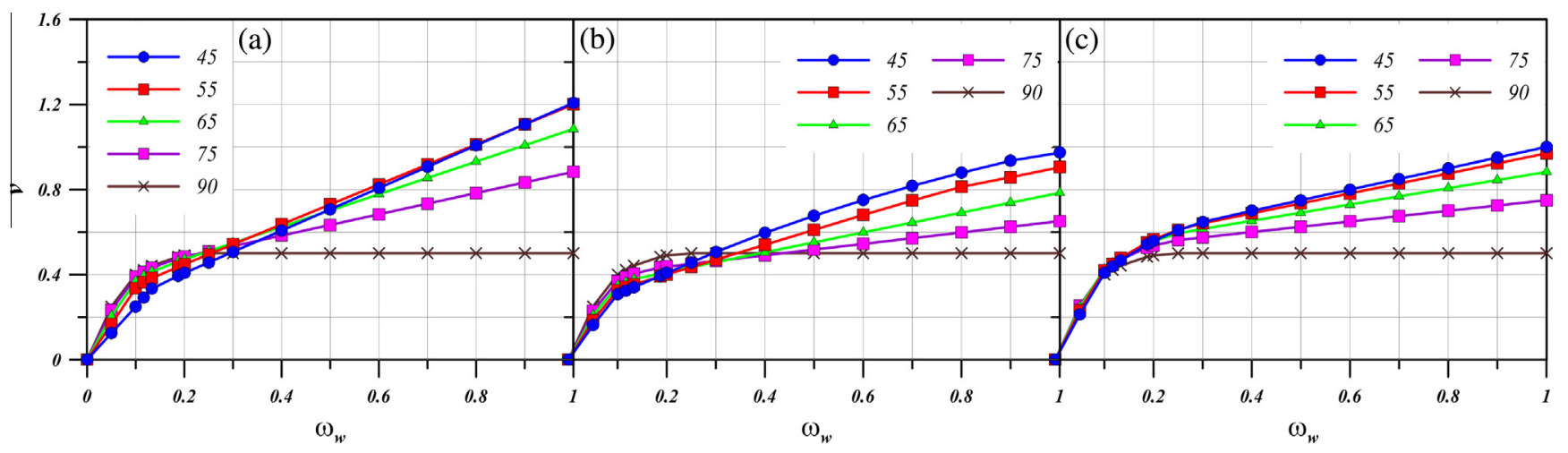

Fig. 7. Non-dimensional shear capacity versus $\omega_{w}$ for $\operatorname{ctg} \theta=2.5$ for layouts $A, B$, and C.

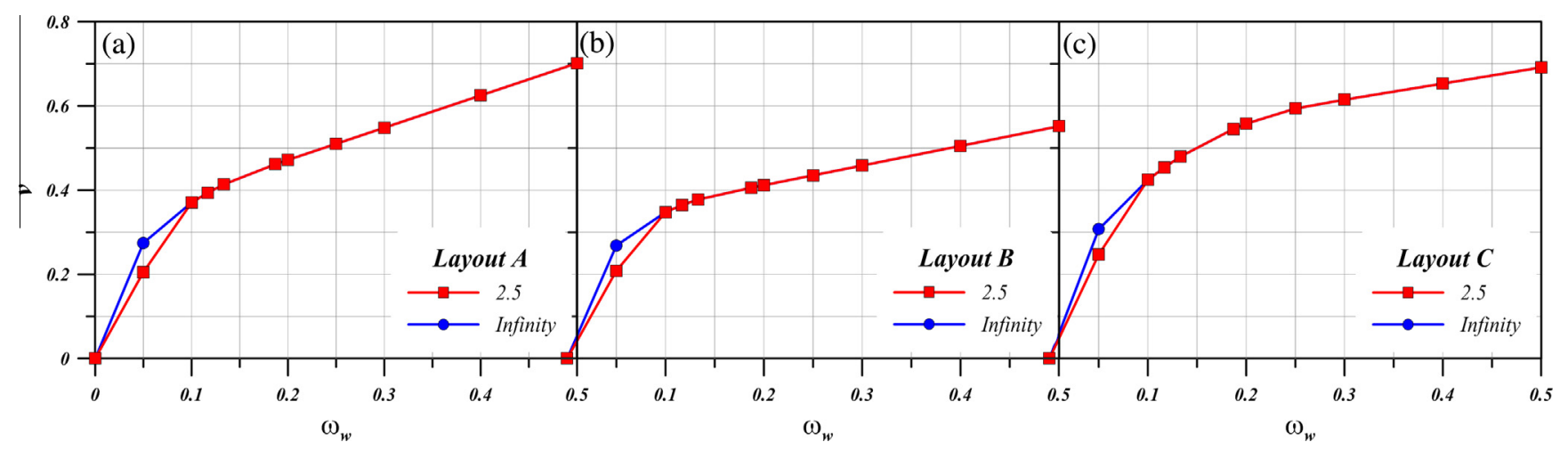

Fig. 8. Non-dimensional shear capacity without limits for $(\operatorname{ctg} \theta)_{\max }$ for layout $\mathrm{A}, \mathrm{B}$ and $\mathrm{C}$.

compression $\left[(\operatorname{ctg} \theta)_{\max }=2.5\right]$ has been investigated by comparing the shear capacities predicted with and without the limitation, i.e. for $\left[(\operatorname{ctg} \theta)_{\max }=2.5\right]$ and $\left[(\operatorname{ctg} \theta)_{\max }=\infty\right]$, respectively, with reference to the three layouts $A, B$ and $C$. The results are reported in Fig. 8.

As an example, for $\alpha=65^{\circ}$ the limitation on $\operatorname{ctg} \theta$ has a rather significant effect only for low values of the mechanical ratio of the stirrups $\left(\omega_{w} \leqslant 0.1\right)$; the role of the limitation $\left[(\operatorname{ctg} \theta)_{\max }=2.5\right]$ is slightly smaller in the layout (c), compared to either (a or b). Finally, it has been shown that in the case of beams transversely reinforced in two directions the limitation on the inclination of the compression field in the web [i.e. on $(\operatorname{ctg} \theta)_{\max }$ ] plays a significant role only in the case of low values of the web-reinforcement mechanical ratio $\left(\omega_{w} \leqslant 0.1\right)$, while it is irrelevant for large values

In the case $\omega_{w}>0.1$, any limitation of $(\operatorname{ctg} \theta)_{\max }$, due to a possible flexural-ductility demand, produce no reductions in the shear capacity.

It has to be emphasized that, when $\omega_{w}=0.1$, value of inclination of stirrups of $45^{\circ}$ provides a value of $(\operatorname{ctg} \theta)_{\max }$ closes to 3.5 , then a pattern with transversal reinforcement arranged perpendicular to one another allows strut angle values smaller than those permitted by codes. With reference to the lower value of $\omega_{w}$ used in Fig. 8 namely $\omega_{w}=0.05$, the $(\operatorname{ctg} \theta)$ values of $4.83,4.57$ and 4.76 for layout $A, B$, and $C$ respectively were found to provide the assessed shear strength.

Adopting value of inclination of stirrups of $45^{\circ}$ for the transversal reinforcement, the width of crack is limited, thus the mechanism of aggregate interlock allows the shear stress transfer. In any cases, the use of the conservative value of $(\operatorname{ctg} \theta)_{\max }=2.5$ in the proposed model is suggested, specially for design.

\section{Concluding remarks}

A previously proposed model was adapted for the evaluation of the shear capacity in RC beams transversely reinforced in two different directions.

The updated model has been derived by extending the plastic model proposed by Nielsen, according to the stress field approach, and it looks like a promising tool for investigating the efficacy of different structural layouts in the design phase.

The model was corroborated by favorable comparison with results of experimental tests on Hybrid Steel Trussed-Concrete Beams and results of numerical analyses, by means of FEM code VecTor2, on RC beams with two orders of stirrups.

Then, a number of parametric analyses have shown, if it is compared to the traditional arrangement (vertical stirrups only), that a noticeable increase in shear capacity can be achieved by placing a second set of inclined stirrups in a suitable direction. The latter depends on the arrangement of the stirrups and on their mechanical ratio.

Moreover, it has been shown that the arrangement of stirrups, only in a vertical position, limits the shear capacity because of the high compression in the concrete stress field, while by introducing a second set of transverse reinforcement (as proposed in this study) it improves the shear capacity, even for extremely high values of the web-reinforcement mechanical ratio.

\section{Acknowledgments}

This work was carried out within the 2014-2017 Research Project “DPC-ReLUIS (Dipartimento Protezione Civile - Rete dei 
Laboratori Universitari di Ingegneria Sismica)", Linea di Ricerca Cemento Armato. The related financial support was greatly appreciated

\section{Appendix A}

In order to derive Eqs. 1-3 linking the external forces to the stress fields, the equilibrium condition of three different beam segments are considered. The first segment of length $x$, is obtained by an inclined section parallel to the direction of the concrete stress field, in order to avoid in equilibrium equations the presence of the compressive stresses acting in the concrete.

In Fig. A1a), $V^{*}$ and $M^{*}$ are the internal forces by acting at the left end of the segment. Denoting with $V_{s d}(x)$ and $M_{s d}(x)$ the bending moment and the shear internal acting in any section $x$, in absence of distributed load, $V^{*}$ and $M^{*}$ are related to $V_{s d}(x)$ and $M_{s d}(x)$ as follows: $V_{s d}(x)=V^{*}$ and $M_{s d}(x)=M^{*}+V^{*} x$.

Referring to the symbols introduced in Fig. A1 and in Section 2, and taking into account that $V_{s d}(x)=V^{*}$, Eq. (1) can be easily derived by conveying the vertical equilibrium condition of segment in Fig. A1a) in the non dimensional form. Moreover, denoting with $\widetilde{C}_{\theta}^{+}$the total force in the compression chord at the section $x+0.5 z \operatorname{ctg} \theta$, made non-dimensional with respect to $b_{w} z f_{c d}^{\prime}$, the non-dimensional form of the equilibrium with respect to point $A$ (Fig. A1) yields:

$$
\begin{aligned}
m(x) & -\widetilde{C}_{\theta}^{+}+\tilde{\sigma}_{t w 1} \omega_{t w 1}\left(\operatorname{ctg} \theta+\operatorname{ctg} \alpha_{1}\right) \sin ^{2} \alpha_{1} \xi \\
& +\tilde{\sigma}_{t w 2} \omega_{t w 2}\left(\operatorname{ctg} \theta+\operatorname{ctg} \alpha_{2}\right) \sin ^{2} \alpha_{2} \xi \\
& +0.5 \tilde{\sigma}_{t w 1} \omega_{t w 1}\left(\operatorname{ctg} \theta+\operatorname{ctg} \alpha_{1}\right) \sin ^{2} \alpha_{1} \operatorname{ctg} \alpha_{1} \\
& +0.5 \tilde{\sigma}_{t w 2} \omega_{t w 2}\left(\operatorname{ctg} \theta+\operatorname{ctg} \alpha_{2}\right) \sin ^{2} \alpha_{2} \operatorname{ctg} \alpha_{2}+0.5 \tilde{\sigma}_{l w} \omega_{l w}=0
\end{aligned}
$$

Inserting Eq. (1) into Eq. (A2), and writing the bending moment at any value of the abscissa $x\left[m(x)=m^{*}+v^{*} \xi\right]$, the following equation can be derived:

$$
\begin{aligned}
m(x) & +0.5\left[\tilde{\sigma}_{t w 1} \cdot \omega_{t w 1} \cdot\left(\operatorname{ctg} \theta+\operatorname{ctg} \alpha_{1}\right) \cdot \sin ^{2} \alpha_{1} \cdot \operatorname{ctg} \alpha_{1}\right. \\
& \left.+\tilde{\sigma}_{t w 2} \cdot \omega_{t w 2} \cdot\left(\operatorname{ctg} \theta+\operatorname{ctg} \alpha_{2}\right) \cdot \sin ^{2} \alpha_{2} \cdot \operatorname{ctg} \alpha_{2}+\tilde{\sigma}_{l w} \omega_{l w} \cdot\right]=\widetilde{C}_{\theta}^{+}
\end{aligned}
$$

In the same way, the equilibrium with respect to point B (Fig. A1) yields:

$$
\begin{aligned}
m(x) & -0.5\left[\tilde{\sigma}_{t w 1} \cdot \omega_{t w 1}\left(\operatorname{ctg} \theta+\operatorname{ctg} \alpha_{1}\right) \cdot \sin ^{2} \alpha_{1} \cdot \operatorname{ctg} \alpha_{1}\right. \\
& \left.+\tilde{\sigma}_{t w 2} \omega_{t w 2}\left(\operatorname{ctg} \theta+\operatorname{ctg} \alpha_{2}\right) \sin ^{2} \alpha_{2} \operatorname{ctg} \alpha_{2}+\tilde{\sigma}_{l w} \cdot \omega_{l w}\right]=\widetilde{T}_{\theta}^{-}
\end{aligned}
$$

where $\widetilde{T}_{\theta}^{-}$is the non-dimensional total force in the tension chord at section $x-0.5 z \operatorname{ctg} \theta$.

To prevent the stress in the second set of stirrups to appear in the equilibrium condition, a second beam segment with the right-end section aligned with the direction of the second set of stirrups (direction $\alpha_{2}$ ) is considered (Fig. A1b).

Hence, Eq. (2) can be easily derived by conveying the vertical equilibrium condition of segment in Fig. A1b in the non-dimensional form.

Then, denoting with $\widetilde{C}_{\alpha 2}^{-}$the non-dimensional form of the total force in the compression chord at the section $x-0.5 z \operatorname{ctg} \alpha_{2}$, in the same way as for Eq. (A2), the equilibrium with respect to point $A$ in Fig. A1b can be enforced as follows:

$$
\begin{aligned}
m(x) & +0.5\left[-\tilde{\sigma}_{c w}\left(\operatorname{ctg} \theta+\operatorname{ctg} \alpha_{2}\right) \sin ^{2} \theta \operatorname{ctg} \theta+\tilde{\sigma}_{l w} \omega_{l w}\right. \\
& \left.+\tilde{\sigma}_{t w 1} \omega_{t w 1}\left(\operatorname{ctg} \alpha_{1}-\operatorname{ctg} \alpha_{2}\right) \sin ^{2} \alpha_{1} \operatorname{ctg} \alpha_{1}\right]=\widetilde{C}_{\alpha 2}^{-}
\end{aligned}
$$

Denoting with $\widetilde{T}_{\alpha 2}^{+}$the non dimensional form of the total force in the tension chord at section $x+0.5 z \operatorname{ctg} \alpha_{2}$, the equilibrium with respect to point $B$ in Fig. A1b, can be enforced as follows:

$$
\begin{aligned}
m(x) & +0.5\left[\tilde{\sigma}_{c w}\left(\operatorname{ctg} \theta+\operatorname{ctg} \alpha_{2}\right) \sin ^{2} \theta \operatorname{ctg} \theta-\tilde{\sigma}_{l w} \omega_{l w}\right. \\
& \left.-\tilde{\sigma}_{t w 1} \omega_{t w 1}\left(\operatorname{ctg} \alpha_{1}-\operatorname{ctg} \alpha_{2}\right) \sin ^{2} \alpha_{1} \operatorname{ctg} \alpha_{1}\right]=\widetilde{T}_{\alpha 2}^{+}
\end{aligned}
$$

The evaluation of the shear capacity can be achieved by rearranging Eqs. (A1)-(A5) in a suitable form, as shown later.

In order to show the consistency of the proposed model, a third beam segment is introduced: this segment is limited by an inclined section at the abscissa $x$, parallel to the first set of stirrups (inclination $\alpha_{1}$, Fig. A1c).

Three equilibrium conditions can be written in the same way as for the first and second segment.

Non-dimensional form of the vertical equilibrium yields Eq. (3).

Denoting with, $\widetilde{C}_{\alpha 1}^{-}$and $\widetilde{T}_{\alpha 1}^{+}$the non-dimensional form of the total forces in the compression and tension chords, at sections $\left(x-0.5 z \operatorname{ctg} \alpha_{1}\right)$ and $\left(x+0.5 z \operatorname{ctg} \alpha_{1}\right)$ shown in Fig. A1c, the equilibrium with respect to point $A$ (Fig. A1c) reads:

$$
\begin{aligned}
m(x) & -0.5 \tilde{\sigma}_{c w}\left(\operatorname{ctg} \theta+\operatorname{ctg} \alpha_{1}\right) \sin ^{2} \theta \operatorname{ctg} \theta-\tilde{\sigma}_{l w} \omega_{l w}+ \\
& \left.-\tilde{\sigma}_{t w 2} \omega_{t w 2}\left(\operatorname{ctg} \alpha_{2}-\operatorname{ctg} \alpha_{1}\right) \sin ^{2} \alpha_{2} \operatorname{ctg} \alpha_{2}\right]=\tilde{C}_{\alpha 1}^{-} z
\end{aligned}
$$

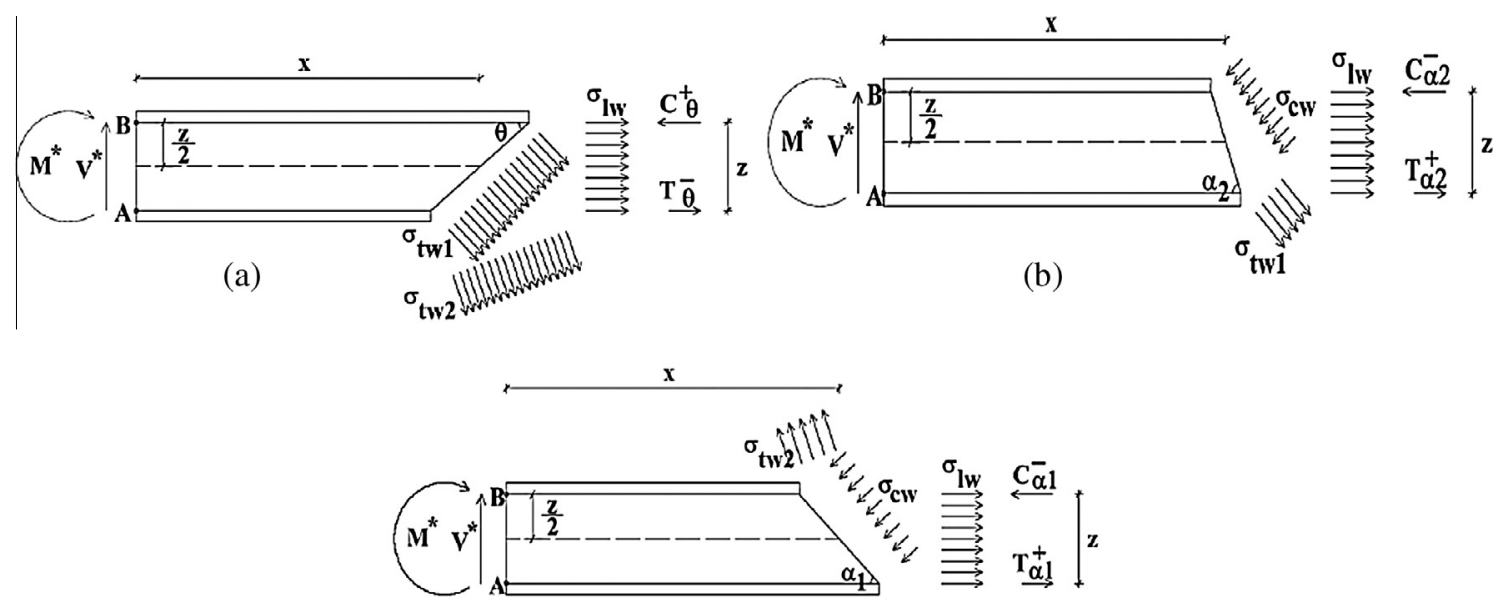

(c)

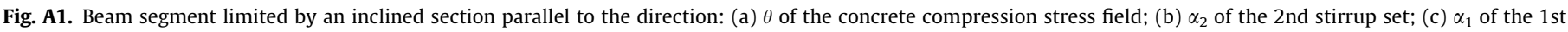
stirrup set. 
Equilibrium with respect to point B (Fig. A1c) yields:

$$
\begin{aligned}
m(x) & +0.5\left[\tilde{\sigma}_{c w} \cdot\left(\operatorname{ctg} \theta+\operatorname{ctg} \alpha_{1}\right) \cdot \sin ^{2} \theta \cdot \operatorname{ctg} \theta-\tilde{\sigma}_{l w} \omega_{s l w}+\right. \\
& \left.-\tilde{\sigma}_{t w 2} \omega_{t w 2}\left(\operatorname{ctg} \alpha_{2}-\operatorname{ctg} \alpha_{1}\right) \cdot \sin ^{2} \alpha_{2} \cdot \operatorname{ctg} \alpha_{2}\right]=\widetilde{T}_{\alpha 1}^{+} z
\end{aligned}
$$

To evaluate the internal force in the tension and compression chord at abscissa $x$, a linear interpolation can be implemented among the values yielded by the previous equations in two of the three considered virtual sections.

A linear interpolation between the results yielded with the virtual sections inclined by $\alpha_{1}$ and $\theta$, or $\alpha_{2}$ and $\theta$, yields respectively:

$\widetilde{C}(x)=\frac{\widetilde{C}_{\alpha_{1}}^{-} \cdot \operatorname{ctg} \theta+\widetilde{C}_{\theta}^{+} \cdot \operatorname{ctg} \alpha_{1}}{\operatorname{ctg} \alpha_{1}+\operatorname{ctg} \theta}=\frac{\widetilde{C}_{\alpha_{2}}^{-} \cdot \operatorname{ctg} \theta+\widetilde{C}_{\theta}^{+} \cdot \operatorname{ctg} \alpha_{2}}{\operatorname{ctg} \alpha_{2}+\operatorname{ctg} \theta}$

for the compression chord, and:

$\widetilde{T}(x)=\frac{\widetilde{T}_{\theta}^{-} \operatorname{ctg} \alpha_{1}+\widetilde{T}_{\alpha_{1}}^{+} \operatorname{ctg} \theta}{\operatorname{ctg} \alpha_{1}+\operatorname{ctg} \theta}=\frac{\widetilde{T}_{\theta}^{-} \operatorname{ctg} \alpha_{2}+\widetilde{T}_{\alpha_{2}}^{+} \operatorname{ctg} \theta}{\operatorname{ctg} \alpha_{2}+\operatorname{ctg} \theta}$

for the tension chord.

Introducing Eqs. (A2) and (A4) into Eq. (A8a), or alternatively Eqs. (A2), (A3) into Eq. (A8b), it yields the following expression for the internal force in the compression chord:

$$
\begin{aligned}
\widehat{C}(x)= & m(x)-0.5\left[\tilde{\sigma}_{c w} \cos ^{2} \theta-\tilde{\sigma}_{t w 1} \omega_{t w 1} \cos ^{2} \alpha_{1}-\tilde{\sigma}_{t w 2} \omega_{t w 2} \cos ^{2} \alpha_{2}\right. \\
& \left.-\tilde{\sigma}_{l w} \omega_{l w}\right]
\end{aligned}
$$

Introducing Eqs. (A5) and (A7) into Eq. (A9a), or alternatively Eqs. (A3), (A5) into Eq. (A9b), it yields the following expression for the internal force in the tension chord:

$$
\begin{aligned}
\widetilde{T}(x)= & m(x)+\left[\tilde{\sigma}_{c w} \cos ^{2} \theta-\tilde{\sigma}_{t w 1} \omega_{t w 1} \cos ^{2} \alpha_{1}-\tilde{\sigma}_{t w 2} \omega_{t w 2} \cos ^{2} \alpha_{2}\right. \\
& \left.-\tilde{\sigma}_{l w} \omega_{l w}\right]
\end{aligned}
$$

Enforcing the equality between the shear capacities provided by Eqs. (1) and (2) it allows to work out the following relationship among the values of the stress fields in the concrete and in the stirrups with two different inclinations:

$\tilde{\sigma}_{c w}=\omega_{t w 1} \cdot \tilde{\sigma}_{t w 1} \cdot \sin ^{2} \alpha_{1} / \sin ^{2} \theta+\omega_{t w 2} \cdot \tilde{\sigma}_{t w 2} \sin ^{2} \alpha_{2} / \sin ^{2} \theta$

Introducing Eq. (A12) into Eqs. (A10), (A11) provides the following simplified expression for the internal forces in the top and bottom chords:

$$
\begin{aligned}
\widehat{C}(x)= & m(x)-0.5\left[\omega_{t w 1} \tilde{\sigma}_{t w 1}\left(\operatorname{ctg}^{2} \theta-\operatorname{ctg}^{2} \alpha_{1}\right) /\left(1+\operatorname{ctg}^{2} \alpha_{1}\right)\right. \\
& \left.+\omega_{t w 2} \tilde{\sigma}_{t w 2}\left(\operatorname{ctg}^{2} \theta-\operatorname{ctg}^{2} \alpha_{2}\right) /\left(1+\operatorname{ctg}^{2} \alpha_{2}\right)-\omega_{l w} \tilde{\sigma}_{l w}\right] \\
\tilde{T}(x)= & \tilde{m}(x)+0.5\left[\omega_{t w 1} \tilde{\sigma}_{t w 1}\left(\operatorname{ctg}^{2} \theta-\operatorname{ctg}^{2} \alpha_{1}\right) /\left(1+\operatorname{ctg}^{2} \alpha_{1}\right)\right. \\
& \left.+\omega_{t w 2} \tilde{\sigma}_{t w 2}\left(\operatorname{ctg}^{2} \theta-\operatorname{ctg}^{2} \alpha_{2}\right) /\left(1+\operatorname{ctg}^{2} \alpha_{2}\right)-\omega_{l w} \tilde{\sigma}_{l w}\right]
\end{aligned}
$$

\section{References}

[1] Leonhardt F, Walther R. Schubversuche an Plattenbalken mit unterschiedlicher Schubbewehrung. Heft 156, W Ernst \& Sohn, Berlin: Deutscher Ausschuss Für Stahlbeton; 1963.

[2] Placas A, Regan PE. Shear failure of reinforced concrete beams. ACI J Proc 1971;68(10):763-73.

[3] Collins MP, Mitchell D, Adebar PE, Vecchio FJ. A general shear design method. ACI Struct J 1996;93(1):36-45.

[4] Rossi PP, Recupero A. Ultimate strength of reinforced concrete circular members subjected to axial force, bending moment and shear force. J Struct Eng 2013. http://dx.doi.org/10.1061/(ASCE)ST.1943-541X.0000724 (Preview Manuscript).

[5] Russo G, Puleri G. Stirrup effectiveness in reinforced concrete beams under flexure and shear. ACI Struct J 1997:94(3):451-76.
[6] Russo G, Somma G, Angeli P. Design shear strength formula for high strength concrete beams. Mater Struct 2004:37(10):680-8. http://dx doi.org/10.1007 BF02480513.

[7] Colajanni P, Recupero A, Spinella N. Design procedure for prestressed concrete beams. Comput Concr 2014;13(2):235-53.

[8] Vecchio FJ, Collins MP. The modified compression field theory for reinforced concrete elements subjected to shear. ACI Struct J 1986;83(2): 219-31.

[9] Lee JY, Kim UY. Effect of longitudinal tensile reinforcement ratio and shear span-depth ratio on minimum shear reinforcement in beams. ACI Struct J 2008;105(2):134-44.

[10] Russo G, Venir R, Pauletta M. Reinforced concrete deep beams-shear strength model and design formula. ACI Struct J 2005;102(3):429-37.

[12] Tompos EJ, Frosch RJ. Influence of beam size, longitudinal reinforcement, and stirrup effectiveness on concrete shear strength. ACI Struct J 2002;99(5): 559-67.

[13] Cho SH. Shear strength prediction by modified plasticity theory for short beams. ACI Struct J 2003;100(1):105-12.

[14] Russo G, Mitri D, Pauletta M. Shear strength design formula for RC beams with stirrups. Eng Struct 2013;51:226-35.

[15] Ritter W. Die Bauweise Hennebique (Construction Techniques of Hennebique). Schweizerische Bauzeitung, Zürich, vol. 33(7); February 1899. p. 59-6.

[16] Mörsch E. Der Eisenbetonbau. Seine Theorie und Anwendung. Stuttgart: Wittwer; 1908.

[17] Bach F, Braestrup MW, Nielsen MP. Rational analysis of shear in reinforced concrete beams. In: I.A.B.S.E. proceedings; 1978. p. 15.

[18] Bertagnoli G, Mancini G, Recupero A, Spinella N. Rotating compression field model for reinforced concrete beams under prevalent shear actions. Struct Concr 2011;12(3):178-86. http://dx.doi.org/10.1002/suco.201000006 abstract. http://onlinelibrary.wiley.com/.

[19] Nielsen MP. Limit analysis and concrete plasticity. 2nd ed. Boca Raton, (Florida, USA): CRC; 1999.

[20] Recupero A, D’Aveni A, Ghersi A. N-M-V interaction domains for box and Ishaped reinforced concrete members. ACI Struct J 2003;100(1):113-9.

[21] Recupero A, D’Aveni A, Ghersi A. Bending moment - shear force interaction domains for prestressed concrete beams. ASCE - J Struct Eng 2005;131(9): 1413-21. http://dx.doi.org/10.1061/(ASCE)0733-9445(2005)131:9(1413).

[22] EC2 - Eurocode No. 2. Design of concrete structures - Part. 1: General rules and rules for buildings - UNI ENV 1992-1-1; 2005

[23] CEB-FIP '90. Model code for concrete structures for buildings, Comitè Eurointernational du Bèton, Lausanne; 1993.

[24] Campione G, Cucchiara C, La Mendola L. Role of fibres and stirrups on the behaviour of reinforced concrete beams under flexure and shear. In: Bruno D, Spadea G, Swamy N, editors. Composite in constructions. Cosenza; 2003. p. 97-102.

[25] Colajanni P, Recupero A, Spinella N. Generalization of shear truss model to the case of SFRC beams with stirrups. Comput Concr 2012;9(3):227-44.

[26] Cucchiara C, La Mendola L, Papia M. Effectiveness of stirrups and steel fibres as shear reinforcement. Cem Concr Compos 26(7):777-786. http://dx.doi.org/ 10.1016/j.cemconcomp.2003.07.001.

[27] Spinella N, Colajanni P, Recupero A. A simple plastic model for shear critical SFRC beams. ASCE J Struct Eng 2010;136(4):390-400. http://dx.doi.org 10.1061/(ASCE)ST.1943-541X.0000127.

[28] Spinella N. Shear strength of full-scale steel fibre-reinforced concrete beams without stirrups. Comput Concr 2013;11(5):365-82.

[29] Colajanni P, La Mendola L, Recupero A. Experimental test results vs. analytical prediction of welding strength in hybrid steel trussed concrete beams (HSTCBs). Eur J Environ Civ Eng 2013;17(8):742-59. http://dx.doi.org/ 10.1080/19648189.2013.815135. ISSN: 2116-7214 (Taylor \& Francis).

[30] Colajanni P, La Mendola L, Monaco A. Experimental studies on stress transfer in hybrid steel trussed-concrete beams. J Constr Steel Res 2014;95:56-70. http://dx.doi.org/10.1016/i.jcsr.2013.11.025. ISSN 0143-974X.

[31] Amadio C, Macorini L, Sorgon S, Suraci S. A novel hybrid system with RCencased steel joists. Eur J Environ Civ Eng 2011;15(10):1433-63.

[32] Chisari C, Amadio C. An experimental, numerical and analytical study of hybrid RC-encased. Eng Struct 2014;61(1):84-98.

[33] PREM Pub. Co. Structural design by using hybrid steel-trussed concrete beams. Milan Italy: PREM. Edizioni Tecniche Nuove; 2011 (in Italian).

[34] Bairan JM, Mari AR. Multiaxial-coupled analysis of RC cross-sections subjected to combined forces. Eng Struct 2007;29(8):1722-38. http://dx.doi.org/ 10.1016/i.engstruct.2006.09.007.

[35] Belletti B, Cerioni R, Iori I. A physical approach for reinforced concrete (PARC) membrane elements. ASCE J Struct Eng 2001;127(12):1421-6.

[36] Bertagnoli G, Carbone VI. A finite element formulation for concrete structures in plane stresses. Struct Concr 2008;9(2):87-99. http://dx.doi.org/10.1680/ stco.2008.9.2.87

[37] Wong PS, Vecchio FJ. Vector2 and formworks users manual. Technical report, Department of Civil Engineering, University of Toronto, Toronto, ON, Canada; 2002. p. 1-232.

[38] Mancini G, Recupero A, Scilipoti CD. Shear in R/C members with longitudinal and transverse web reinforcement. Stud Res, Spec School Des of R/C Struct "Fratelli Pesenti", Politecnico di MilanoMilan (Italy) 1996;17:301-17.

[39] Colajanni P, Mancini G, Recupero A. Degradation effects in N-M-V interaction domains for $\mathrm{R} / \mathrm{C}$ members subjected to seismic loading (in Italian). In: Proc. 12th nat conference "L'Ingegneria Sismica in Italia" (Seismic Engineering in 
Italy), organized by Anidis - Italian Society of Seismic Engineering, Pisa (Italy), June 10-14, on CD; 2007.

[40] Colajanni P, Recupero A, Spinella N. Shear strength degradation due to ductility demand in circular R.C. columns. Proposed for publication on Bulletin of Earthquake Engineering.
[41] Nash SG, Sofer A. Linear and nonlinear programming. Boston: McGraw-Hill; 1996.

[42] Vecchio FJ. Disturbed stress field model for reinforced concrete: formulation. ASCE J Struct Eng 2000;126(9):1070-7. 